\title{
Thirty years of research on autonomic dysfunction, non-motor features, and endophenotypes in Parkinson disease
}

\author{
K. Ray Chaudhuri ${ }^{1}$
}

Received: 4 January 2021 / Accepted: 5 January 2021 / Published online: 30 January 2021

(c) Springer-Verlag GmbH Germany, part of Springer Nature 2021

Keywords Dysautonomia; parkinson disease $\cdot$ Nonmotor $\cdot$ Nonmotor subtypes $\cdot$ Endophenotypes $\cdot$ Splanchnic . Personalized medicine

I congratulate Clinical Autonomic Research on its thirtieth anniversary. Among the articles included in its first issue are two manuscripts which I co-authored with the founding editor in chief of the journal, Christopher Mathias, and others $[5,13]$. This brief piece is my perspective on the evolution of autonomic research in Parkinson disease over the last thirty years.

In the 1990s, I moved to London to work in the Pickering unit at St Mary's Hospital and the National Hospital of Neurology at Queen Square to start my research on autonomic dysfunction in humans, both healthy ones and those with neurodegeneration. Coming from a busy medical practice in the midlands, this was a new world to me. I learned about the role of vascular regulation of the brain and the gut and how this played such a key role in autonomic control while researching the neural and hormonal basis of splanchnic vascular autonomic control [5]. In hindsight, aspects of this important period of research contributed significantly to my future research on the holistic spectrum of non-motor features in parkinsonism.

How has this area of neuroscience evolved, since the original days of research when we were trying to unravel issues related to the impact of splanchnic vascular autonomic control on the brain [6], postprandial hypotension [2], and other pathophysiological aspects of autonomic dysfunction? One of the first issues to consider is the diagnostic criteria for Parkinson disease. In the 1990s, we worked on the identification of neuropharmacological and neuroendocrine

K. Ray Chaudhuri

ray.chaudhuri@kcl.ac.uk

1 Department of Basic and Clinical Neuroscience, Parkinson Foundation International Centre of Excellence, Kings College Hospital and Kings College London, Cutcombe Road, London SE5 9RT, England, UK biomarkers to distinguish between Parkinson disease and multiple system atrophy. One of those was intravenous clonidine, a centrally-acting alpha-adrenergic receptor agonist that inhibits the turnover rate of brain noradrenaline and charting its effect on growth hormone [18]. Although this method is rarely used today, it is nevertheless an elegant way to distinguish central vs. peripheral defects in patients with parkinsonism.

Also, the role of cardiac metaiodobenzylguanidine (MIBG) scintigraphy which specifically binds to noradrenaline transporters in the heart was becoming evident as a possible marker of cardiac noradrenergic innervation [1]. Today we know that, while normal cardiac innervation almost certainly excludes Parkinson disease, abnormal cardiac innervation does not necessarily exclude multiple system atrophy, as a minority of patients with the latter have some degree of peripheral noradrenergic damage.

In 2015, the Movement Disorders Society revisited the diagnostic criteria for Parkinson disease and published revised updated criteria in which an abnormal cardiac MIBG scan was considered a specific supportive criterion [16]. More recently, a "body first" vs. "brain first" hypothesis has been proposed to explain the pathophysiologic basis of Parkinson disease and some of the phenotypic differences [8]. The "body first" concept is underpinned by abnormalities of gut microbiota and activation of the sympathetic connectome to the heart resulting in an abnormal cardiac MIBG scan and also the "gut-brain" pathway via the vagus nerve to the pontine and brainstem vagal nuclei. Ascending pathology affects pontine structures which may express premotor features of Parkinson disease, such as rapid eye movement (REM) sleep behavior disorder (RBD). This hypothesis is supported by the fact that many patients with Parkinson disease have a prodromal, autonomic-only phase, usually referred to as pure autonomic failure (PAF). On autopsy, patients with 
PAF have alpha-synuclein deposits in peripheral autonomic nerves, but not in the CNS [7, 9]. Prospective studies have demonstrated that a substantial number of patients with PAF will end up developing Parkinson disease and dementia with Lewy bodies [10]. Autonomic dysfunction is, therefore, now at the heart of the diagnostic and pathophysiological concept of Parkinson disease.

Another area that has developed is the integration of autonomic dysfunction as a core concept of the wide range of non-motor features, which significantly contribute to reduced quality of life of patients with Parkinson disease. Autonomic function is an essential constituent of the newly developed holistic tools for bedside assessment of non-motor symptoms in Parkinson disease, such as the SCOPA-Autonomic and MDS-NMS scales, the latter being based on the Parkinson disease non-motor symptom scale (NMSS) [3, 4]. The NMSS was developed by an international group led by me as the first holistic tool dedicated to non-motor symptoms of Parkinson disease [3]. The NMSS has been widely used worldwide for the global assessment of nonmotor symptoms in epidemiological, clinical, and clinical trial-based research in Parkinson disease and has highlighted the important role of the autonomic domains ranging from gastrointestinal to cardiac in the clinical assessment of Parkinson disease.

Prognostic markers have been identified, such as constipation, which has been linked to cognitive dysfunction as a non-motor predictor in a recent cohort study [11]. Several large studies have addressed non-motor features using cluster analysis, and autonomic dysfunction has invariably played a major role in disease progression as well as clinical expression. For instance, the ONSET PD study, a cross-sectional study using non-motor symptoms questionnaires, identified four dominant clusters of features, and two of these, the "sensory and autonomic dysfunction" cluster, and the "RBD and constipation" cluster identified autonomic dysfunction as part of specific phenotypes of Parkinson disease [15]. An analysis of recent studies has translated these findings to the clinic, and several clinical endophenotypes of Parkinson disease have been proposed and published based on clinical symptoms as well as probable underlying neurotransmitter dysfunction [17]. For instance, the "noradrenergic subtype" is specifically characterized by autonomic dysfunction.

The above observations are not just academic curiosities or examples of research without external validity. A key development in the management of Parkinson disease, the fastest growing neurodegenerative disorder in the world, is a truly comprehensive and personalized medicine strategy that incorporates the key principle that "one size does not fit all" when it comes to preparing treatment paradigms for patients with Parkinson disease [19]. This strategy focuses on several elements, and one of them is subtype-specific treatment, which, as of right now, is only symptomatic.
Autonomic dysfunction, as applied to Parkinson disease, can drive specific subtype-based treatment strategies and has been highlighted in several reviews [12]. As an example, the "noradrenergic subtype", therefore, needs specific attention to the gastrointestinal system, and consideration of early non-oral therapies because of delayed gastric absorption. Constipation, sialorrhea as well as dysphagia needs interventions while both early and delayed orthostatic hypotension need to be considered [14].

I feel rewarded that my early days at the Pickering unit with the giants in the field, such as Prof. Chris Mathias, the late Prof. David Marsden, and many other colleagues did bear important fruits for the future. Specifically, in my case, it opened up a new world of non-motor research in Parkinson disease, features that were recognized by Dr. James Parkinson himself in his seminal 1817 essay but broadly neglected by the general neurologists until the twenty-first century. Progress thereafter has been phenomenal and non-motor features are now recognized as integral to the concept of Parkinson disease and non-motor subtyping, the latter leading the way to personalized medicine. This progress is a shining example of how researching the relatively unknown can lead to better treatment for the millions of patients afflicted with Parkinson disease globally.

Funding None.

\section{Compliance with ethical standards}

Conflict of interests None.

\section{References}

1. Braune S, Reinhardt M, Schnitzer R, Riedel A, Lucking $\mathrm{CH}$ (1999) Cardiac uptake of [123I]MIBG separates Parkinson's disease from multiple system atrophy. Neurology 53:1020-1025

2. Chaudhuri KR, Ellis C, Love-Jones S, Thomaides T, Clift S, Mathias CJ, Parkes JD (1997) Postprandial hypotension and parkinsonian state in Parkinson's disease. Mov Disord 12:877-884

3. Chaudhuri KR, Martinez-Martin P, Brown RG, Sethi K, Stocchi F, Odin P, Ondo W, Abe K, Macphee G, Macmahon D, Barone P, Rabey M, Forbes A, Breen K, Tluk S, Naidu Y, Olanow W, Williams AJ, Thomas S, Rye D, Tsuboi Y, Hand A, Schapira AH (2007) The metric properties of a novel non-motor symptoms scale for Parkinson's disease: results from an international pilot study. Mov Disord 22:1901-1911

4. Chaudhuri KR, Schrag A, Weintraub D, Rizos A, RodriguezBlazquez C, Mamikonyan E, Martinez-Martin P (2020) The movement disorder society nonmotor rating scale: initial validation study. Mov Disord 35:116-133

5. Chaudhuri KR, Thomaides T, Hernandez P, Alam M, Mathias CJ (1991) Noninvasive quantification of superior mesenteric artery blood flow during sympathoneural activation in normal subjects. Clin Auton Res 1:37-42 
6. Chaudhuri KR, Thomaides T, Mathias CJ (1992) Abnormality of superior mesenteric artery blood flow responses in human sympathetic failure. J Physiol 457:477-489

7. Hague K, Lento P, Morgello S, Caro S, Kaufmann H (1997) The distribution of Lewy bodies in pure autonomic failure: autopsy findings and review of the literature. Acta Neuropathol 94:192-196

8. Horsager J, Andersen KB, Knudsen K, Skjaerbaek C, Fedorova TD, Okkels N, Schaeffer E, Bonkat SK, Geday J, Otto M, Sommerauer M, Danielsen EH, Bech E, Kraft J, Munk OL, Hansen SD, Pavese N, Goder R, Brooks DJ, Berg D, Borghammer P (2020) Brain-first versus body-first Parkinson's disease: a multimodal imaging case-control study. Brain 143:3077-3088

9. Kaufmann H, Hague K, Perl D (2001) Accumulation of alphasynuclein in autonomic nerves in pure autonomic failure. Neurology 56:980-981

10. Kaufmann H, Norcliffe-Kaufmann L, Palma JA, Biaggioni I, Low PA, Singer W, Goldstein DS, Peltier AC, Shibao CA, Gibbons CH, Freeman R, Robertson D, Autonomic Disorders C (2017) Natural history of pure autonomic failure: a United States prospective cohort. Ann Neurol 81:287-297

11. Leta V, Urso D, Batzu D, Weintraub D, Aarsland D, van Wamelen D, Yousaf P, Martinez-Martin P, Rodriguez-Blazquez C, Rizos A, Chaudhuri KR (2020) Does constipation predict cognitive impairment and dementia in de novo Parkinson's disease patients? A multi-cohort longitudinal data analysis [abstract]. . Mov Disord 35

12. Marras C, Chaudhuri KR, Titova N, Mestre TA (2020) Therapy of Parkinson's Disease Subtypes. Neurotherapeutics
13. Mathias CJ, Armstrong E, Browse N, Chaudhuri KR, Enevoldson P, Russell RW (1991) Value of non-invasive continuous blood pressure monitoring in the detection of carotid sinus hypersensitivity. Clin Auton Res 1:157-159

14. Palma JA, Kaufmann H (2018) Treatment of autonomic dysfunction in Parkinson disease and other synucleinopathies. Mov Disord 33:372-390

15. Pont-Sunyer C, Hotter A, Gaig C, Seppi K, Compta Y, Katzenschlager R, Mas N, Hofeneder D, Brucke T, Bayes A, Wenzel K, Infante J, Zach H, Pirker W, Posada IJ, Alvarez R, Ispierto L, De Fabregues O, Callen A, Palasi A, Aguilar M, Marti MJ, Valldeoriola F, Salamero M, Poewe W, Tolosa E (2015) The onset of nonmotor symptoms in Parkinson's disease (the ONSET PD study). Mov Disord 30:229-237

16. Postuma RB, Berg D, Stern M, Poewe W, Olanow CW, Oertel W, Obeso J, Marek K, Litvan I, Lang AE, Halliday G, Goetz CG, Gasser T, Dubois B, Chan P, Bloem BR, Adler CH, Deuschl G (2015) MDS clinical diagnostic criteria for Parkinson's disease. Mov Disord 30:1591-1601

17. Sauerbier A, Jenner P, Todorova A, Chaudhuri KR (2016) Non motor subtypes and Parkinson's disease. Parkinsonism Relat Disord 22(Suppl 1):S41-46

18. Thomaides TN, Chaudhuri KR, Maule S, Watson L, Marsden CD, Mathias CJ (1992) Growth hormone response to clonidine in central and peripheral primary autonomic failure. Lancet 340:263-266

19. Titova N, Chaudhuri KR (2017) Personalized medicine in Parkinson's disease: Time to be precise. Mov Disord 32:1147-1154 